\title{
Development and Validation of HPLC Method for the Simultaneous Determination of Five Food Additives and Caffeine in Soft Drinks
}

\author{
Bürge Aşçı, Şule Dinç Zor, and Özlem Aksu Dönmez \\ Department of Chemistry, Faculty of Science and Arts, Yildiz Technical University, Davutpasa, 34220 Istanbul, Turkey
}

Correspondence should be addressed to Şule Dinç Zor; sule_dinc@yahoo.com

Received 9 December 2015; Revised 19 January 2016; Accepted 20 January 2016

Academic Editor: Josep Esteve-Romero

Copyright (C) 2016 Bürge Aşçı et al. This is an open access article distributed under the Creative Commons Attribution License, which permits unrestricted use, distribution, and reproduction in any medium, provided the original work is properly cited.

\begin{abstract}
Box-Behnken design was applied to optimize high performance liquid chromatography (HPLC) conditions for the simultaneous determination of potassium sorbate, sodium benzoate, carmoisine, allura red, ponceau $4 \mathrm{R}$, and caffeine in commercial soft drinks. The experimental variables chosen were $\mathrm{pH}(6.0-7.0)$, flow rate $(1.0-1.4 \mathrm{~mL} / \mathrm{min})$, and mobile phase ratio (85-95\% acetate buffer). Resolution values of all peak pairs were used as a response. Stationary phase was Inertsil OctaDecylSilane- (ODS-) 3V reverse phase column $(250 \times 4.6 \mathrm{~mm}, 5 \mu \mathrm{m})$ dimensions. The detection was performed at $230 \mathrm{~nm}$. Optimal values were found $6.0 \mathrm{pH}$, $1.0 \mathrm{~mL} / \mathrm{min}$ flow rate, and 95\% mobile phase ratio for the method which was validated by calculating the linearity $\left(r^{2}>0.9962\right)$, accuracy (recoveries $\geq 95.75 \%$ ), precision (intraday variation $\leq 1.923 \%$, interday variation $\leq 1.950 \%$ ), limits of detection (LODs), and limits of quantification (LOQs) parameters. LODs and LOQs for analytes were in the range of $0.10-0.19 \mu \mathrm{g} / \mathrm{mL}$ and $0.33-$ $0.63 \mu \mathrm{g} / \mathrm{mL}$, respectively. The proposed method was applied successfully for the simultaneous determination of the mixtures of five food additives and caffeine in soft drinks.
\end{abstract}

\section{Introduction}

Food additives are widely used in foodstuffs to prevent from spoilage and improve color, flavor, and texture of foods. However, these additives in foods may affect individuals who are sensitive with some type of allergy, asthma, and hay fever. Consequently, authorities have set threshold values for acceptable daily intake, varying from country to country. For instance, the list of authorised food additives and maximum permitted levels in European Union are laid down in the annexes of council directive $[1,2]$.

To ensure food safety from farm to fork, it is also essential to develop effective and reliable analytical methods for the monitoring of the additive levels in food [3]. Therefore, various analytical methods have been reported for the simultaneous determination synthetic food additives, such as thin layer chromatography [4], UV-visible spectrophotometry [5, 6], voltammetry $[7,8]$, differential pulse polarography [9], capillary electrophoresis [10], HPLC-DAD [11-14], HPLCMS [15], and HPLC-MS-MS [16, 17]. Until now, although many analytical techniques have been developed for the determination of various food additives in foods, there is no report about simultaneous determination of this combination in food samples. Among these analytical methods, HPLC coupled with UV/Vis or diode array detectors (DADs) are the most commonly used methods due to their sensitivity, selectivity, and high resolution. So, development of effective chromatographic separation method involves judicious selection of experimental conditions that is suitable for the separation of interested components at an adequate resolution with reasonable run time. In this regard, experimental design is a useful tool to simplify the laborious work [18]. It not only is a timesaving method but also it has an ability to reveal possible interactions between variables $[19,20]$. Hence, experimental designs have been increasingly used to determine the optimum conditions of chromatographic separation of some analytes in food, drug, and biological fluid samples with a minimum number of experiments for over the past decade [21-28]. 
In this paper, a new RP-HPLC method was developed, using experimental design, for simultaneous determination of five synthetic food additives in soft drinks, including three synthetic colorants (carmoisine, allura red, and ponceau 4R), two preservatives (potassium sorbate and sodium benzoate), and caffeine. For the optimization procedure, BoxBehnken design (BBD) was used to construct mathematical models that predict how changes input or controlled by variables $(\mathrm{pH}$, flow rate, and mobile phase ratio) affected the resolution in defined experimental region. Further, the method validation has been carried out according to the International Conference on Harmonization guidelines. The optimized and validated method was successfully applied to some commercial soft drinks containing potassium sorbate, sodium benzoate, carmoisine, allura red, ponceau $4 \mathrm{R}$, and caffeine.

\section{Experimental}

2.1. Apparatus. Chromatographic analyses were performed using a Shimadzu HPLC system (Kyoto, Japan) consisting of a model LC20 AT pump unit, SPD-20A UV-Vis detector, $772520 \mu \mathrm{L}$ sample injection, a computer, and an Inertsil OctaDecylSilane- (ODS-) 3V column $(5 \mu \mathrm{m}, 250 \mathrm{~mm} \times$ $4.6 \mathrm{~mm}$; GL Sciences, Tokyo, Japan). The statistical analysis for the analytical responses and validation data was evaluated with Microsoft Excel 2000 software. The statistical software Statgraphics Centurion XV (StatPoint Inc., VA, USA) was used for the graph plotting and for estimating the responses of experimental variables.

2.2. Chemicals and Reagents. All chemicals and solvents were of analytical reagent grade and used without further purification. Milli-Q water was used to prepare the solutions and mobile phases (Millipore, Milford, MA, USA). Sodium acetate trihydrate, glacial acetic acid, and HPLCgrade acetonitrile were acquired from Merck (Darmstadt, Germany). Potassium sorbate ( $\geq 99.0 \%$ purity), sodium benzoate ( $\geq 99.0 \%$, purity), carmoisine ( $\geq 98.0 \%$ purity), allura red $(\geq 98.0 \%$ purity), ponceau $4 \mathrm{R}$ ( $\geq 99.0 \%$ purity), and caffeine (100.0\% purity) were purchased from Sigma-Aldrich (St. Louis, Missouri, USA).

2.3. Preparation of Standard Solutions. Standard stock solutions of potassium sorbate, sodium benzoate, and caffeine were prepared at a concentration of $250 \mu \mathrm{g} / \mathrm{mL}$. Standard stock solutions of carmoisine, allura red, and ponceau $4 \mathrm{R}$ were prepared at a concentration of $100 \mu \mathrm{g} / \mathrm{mL}$. Fresh working solutions in the concentration range of $2-10 \mu \mathrm{g} / \mathrm{mL}$ for carmoisine, allura red, and ponceau $4 \mathrm{R}$ and $5-25 \mu \mathrm{g} / \mathrm{mL}$ for caffeine, potassium sorbate, and sodium benzoate were prepared by the dilution of the standard stock solutions in Milli-Q water.

2.4. Sample Preparation. Soft drink samples were purchased from local supermarkets in Istanbul, Turkey, and were degassed in an ultrasonic bath for $5 \mathrm{~min}$. Then, $1 \mathrm{~mL}$ of the sample was transferred to a $10 \mathrm{~mL}$ volumetric flask and diluted to the volume with Milli-Q water. Prior to the analysis,
TABLE 1: The experimental variables and levels of BBD.

\begin{tabular}{lccc}
\hline Variable & \multicolumn{3}{c}{ Level } \\
& -1 & 0 & +1 \\
\hline $\mathrm{pH}(A)$ & 6.0 & 6.5 & 7.0 \\
Flow rate $(B)\left(\mathrm{mL} \mathrm{min}^{-1}\right)$ & 1.0 & 1.2 & 1.4 \\
Mobile phase ratio $(C)(\%)$ & 85 & 90 & 95 \\
\hline
\end{tabular}

both soft drink samples and standard solutions were filtered through $0.45 \mu \mathrm{m}$ Millipore filters and then injected into HPLC system.

2.5. Chromatographic Procedure. The optimum separation of all analytes was achieved with $0.025 \mathrm{M}$ sodium acetate/acetic acid buffer, $\mathrm{pH} 6.0$, acetonitrile gradient that follows $0-5 \mathrm{~min}$, $95: 75(\mathrm{v} / \mathrm{v}) ; 5-10 \mathrm{~min}, 70: 30(\mathrm{v} / \mathrm{v})$. The mobile phase flow rate was $1.0 \mathrm{~mL} / \mathrm{min}$ and the injection volume was $20 \mu \mathrm{L}$ in all the chromatographic runs. The detection was made with a variable ultraviolet-visible detector fixed at $230 \mathrm{~nm}$.

2.6. Optimization Procedure. A Box-Behnken design (BBD) using three variables at three levels (coded levels: $-1,0$, and +1 ) was used for the optimization of simultaneous determination of potassium sorbate, sodium benzoate, carmoisine, allura red, ponceau $4 \mathrm{R}$, and caffeine by HPLC. This design was selected due to the small number of experiments required. The variables and levels selected for optimization procedure were $\mathrm{pH}(A ; 6.0,6.5$, and 7.0$)$, flow rate $(B ; 1.0,1.2$, and 1.4), and mobile phase ratio (in terms of acetate buffer) $(C ; 85,90$, and 95) (Table 1). The proposed HPLC method analyzed the compounds in two steps as mentioned above. While the first step has an effect on the chromatographic separation, the second step has an effect on the run time of the method. Therefore, experimental variables of the first step of HPLC method were taken into account. 15 experimental runs were performed at random and overall resolution $(R)$ was chosen as the response for the separation of the compounds [19]. Experimental design matrix used and the results obtained by BBD were listed in Table 2 .

2.7. Validation Procedure. In-house validation of the method was performed according to International Conference on Harmonization guidelines (ICH Q2R1) [29]. Evaluated parameters are linearity of calibration curve, limit of detection (LOD), limit of quantification (LOQ), and precision, accuracy, and stability. The linearity of the HPLC method for the determination of five food additives and caffeine was evaluated in a concentration range of $2-10 \mu \mathrm{g} / \mathrm{mL}$ for carmoisine, allura red, and ponceau $4 \mathrm{R}$ and $5-25 \mu \mathrm{g} / \mathrm{mL}$ for potassium sorbate, sodium benzoate, and caffeine covering the normal range of concentrations obtained when analyzing soft drinks. Calibration equations were calculated by the least squares treatment of the peak area of the food additives and caffeine. The limit of detection (LOD) and limit of quantitation (LOQ) were calculated as LOD $3 x \sigma / S$ and LOQ $10 x \sigma / S$, where $\sigma$ is the standard deviation of intercept and $S$ is the slope. In order to test the prediction performance of the proposed methods, intraday (three times in a day operation 
TABLE 2: Experimental design matrix and the responses for BBD.

\begin{tabular}{lcccc}
\hline Run & $A$ & $B$ & $C$ & $R$ \\
\hline 1 & 6.0 & 1.0 & 90 & 1.041 \\
2 & 7.0 & 1.0 & 90 & 0.622 \\
3 & 6.0 & 1.4 & 90 & 0.553 \\
4 & 7.0 & 1.4 & 90 & 0.128 \\
5 & 6.0 & 1.2 & 85 & 0.000 \\
6 & 7.0 & 1.2 & 85 & 0.027 \\
7 & 6.0 & 1.2 & 95 & 3175.373 \\
8 & 7.0 & 1.2 & 95 & 1792.207 \\
9 & 6.5 & 1.0 & 85 & 0.046 \\
10 & 6.5 & 1.4 & 85 & 0.000 \\
11 & 6.5 & 1.0 & 95 & 2487.823 \\
12 & 6.5 & 1.4 & 95 & 1257.455 \\
13 & 6.5 & 1.2 & 90 & 0.759 \\
14 & 6.5 & 1.2 & 90 & 0.327 \\
15 & 6.5 & 1.2 & 90 & 0.918 \\
\hline
\end{tabular}

under the same conditions) and interday (four different days) studies were performed at three different concentrations (Level 1: $10 \mu \mathrm{g} / \mathrm{mL}$; Level 2: $15 \mu \mathrm{g} / \mathrm{mL}$; Level 3: $20 \mu \mathrm{g} / \mathrm{mL}$ for potassium sorbate, sodium benzoate, and caffeine; Level 1 : $4 \mu \mathrm{g} / \mathrm{mL}$; Level 2: $6 \mu \mathrm{g} / \mathrm{mL}$; Level 3: $8 \mu \mathrm{g} / \mathrm{mL}$ for carmoisine, allura red, and ponceau 4R). Accuracy of the method was ascertained by a recovery study by adding a known amount of reference standards to the soft drink samples. Firstly, $0.5 \mathrm{~mL}$ of the soft drink sample was transferred to a $10 \mathrm{~mL}$ volumetric flask and the reference standards were added on it at three different concentration levels. Then, added samples were diluted to the volume with Milli-Q water, filtered, and analyzed.

\section{Results and Discussion}

3.1. Optimization of the HPLC Method. Chromatographic optimization requires selecting suitable criteria for the evaluation of the resultant chromatograms in order to choose the optimum conditions. BBD is an independent, rotatable, or nearly rotatable second-order design based on three-level incomplete factorial designs. It is more efficient compared to other response surface designs, such as central composite designs. It can also provide sufficient information to test the lack of fit, and therefore it is one of the best quadratic models for response surface method and has been widely used in analytical fields. Because of the nonlinearity of the model, a polynomial function to contain second-order model is postulated to describe the evolution phenomenon:

$$
y_{i}=b_{0}+\sum_{i=1}^{n} b_{i} x_{i}+\sum_{i=1}^{n} b_{i i} x_{i}^{2}+\sum_{1 \leq i \leq j}^{n} b_{i j} x_{i} x_{j}+\varepsilon_{i},
$$

where $n$ is the number of variables, $b_{0}$ is the constant term, $b_{i}$, $b_{i i}$, and $b_{i j}$ represent the coefficient of the first-order terms, quadratic terms, and interaction terms, respectively, and $\varepsilon_{i}$ is a term that represents other sources of variability not accounted for the estimation, such as background noise [30].
TABLE 3: ANOVA results for optimization by BBD.

\begin{tabular}{lccccc}
\hline Effect & SS & D.f. & MS & $F$-ratio & $P$ value \\
\hline$A$ & 239422 & 1 & 239422 & 1.95 & 0.2216 \\
$B$ & 189543 & 1 & 189543 & 1.54 & 0.2694 \\
$C$ & 9489050 & 1 & 9489050 & 77.20 & $0.0003^{*}$ \\
$A A$ & 86144 & 1 & 86144 & 0.70 & 0.4407 \\
$A B$ & 0 & 1 & 0 & 0.00 & 1.0000 \\
$A C$ & 478304 & 1 & 478304 & 3.89 & 0.1056 \\
$B B$ & 86239 & 1 & 86239 & 0.70 & 0.4404 \\
$B C$ & 378422 & 1 & 378422 & 3.08 & 0.1397 \\
$C C$ & 4374670 & 1 & 4374670 & 35.59 & $0.0019^{*}$ \\
Total error & 614539 & 5 & 122908 & & \\
Total (corr.) & 15999393 & 14 & & & \\
\hline
\end{tabular}

SS: sum of squares; MS: mean squares; $F$-ratio: $\mathrm{MS} \mathrm{MS}_{\text {error }}$; $P$ value: probability level; D.f.: degree of freedom.

$R^{2}=0.961, R^{2}$ (adjusted for D.f.) $=0.892$.

${ }^{*}$ Significant factor at $\alpha=0.05$.

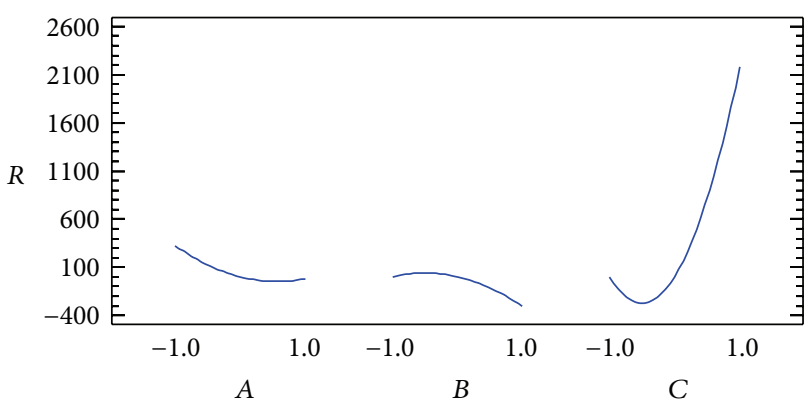

Figure 1: Analysis of the main variables in BBD.

The experimental results are shown in Table 2. The regression model for the response was tested through analysis of variance (ANOVA). From the results of ANOVA (Table 3), it can be deduced that linear contribution of mobile phase ratio $(C)$ and quadratic contribution of mobile phase ratio (CC) influence the resolution significantly. Interactions of the individual variables in this study are not significant to resolution in the selected range. Fitted quadratic model equation is also presented in (2). Figure 1 shows the analysis of individual variables of experimental design. From Figure 1, it can be seen how the value of the resolution may increase if we take higher mobile phase ratio $(C)$. Also, we can infer that although $\mathrm{pH}(A)$ and flow rate $(B)$ do not greatly influence the resolution better resolutions are obtained for low values of $\mathrm{pH}$ and flow rate

$$
\begin{aligned}
\widehat{R}= & 0.67-172.99 A-153.92 B+1089.10 C \\
& +152.74 A^{2}-345.80 A C-152.83 B^{2}-307.58 B C \\
& +1088.49 C^{2}
\end{aligned}
$$

The regression models obtained were used to calculate the response surface for each variable separately. Figure 2 illustrates the response surface plots for the resolutions. In 
TABLE 4: The important parameters of the calibration equations for the proposed HPLC method for simultaneous determination of potassium sorbate (SOR), sodium benzoate (BEN), carmoisine (CAR), allura red (ALU), ponceau 4R (PON), and caffeine (CAF).

\begin{tabular}{lcccccc}
\hline Compounds & $\begin{array}{c}\text { Calibration range } \\
(\mu \mathrm{g} / \mathrm{mL})\end{array}$ & $\begin{array}{c}\text { Regression equation } \\
(Y=a X+b)\end{array}$ & $S_{a}$ & $S_{b}$ & $\begin{array}{c}r^{2} \\
(\mu \mathrm{g} / \mathrm{mL})\end{array}$ & $\begin{array}{c}\text { LOQ } \\
(\mu \mathrm{g} / \mathrm{mL})\end{array}$ \\
\hline SOR & $5-25$ & $Y=7.8097 \times 10^{4} X+4.6484 \times 10^{4}$ & $1.391 \times 10^{3}$ & $2.3076 \times 10^{4}$ & 0.9990 & 0.12 \\
BEN & $5-25$ & $Y=3.3313 \times 10^{4} X+1.2421 \times 10^{4}$ & $7.52 \times 10^{2}$ & $1.2469 \times 10^{4}$ & 0.9985 & 0.10 \\
CAR & $2-10$ & $Y=4.3383 \times 10^{4} X+1.8834 \times 10^{4}$ & $6.86 \times 10^{2}$ & $4.555 \times 10^{3}$ & 0.9992 & 0.16 \\
ALU & $2-10$ & $Y=5.5741 \times 10^{4} X-7.427 \times 10^{3}$ & $9.22 \times 10^{2}$ & $1.5292 \times 10^{4}$ & 0.9992 & 0.11 \\
PON & $2-10$ & $Y=6.043 \times 10^{3} X+5.0389 \times 10^{4}$ & $2.150 \times 10^{3}$ & $1.4264 \times 10^{4}$ & 0.9962 & 0.17 \\
CAF & $5-25$ & $Y=2.4885 \times 10^{4} X+4.6613 \times 10^{4}$ & $4.81 \times 10^{2}$ & $3.1891 \times 10^{4}$ & 0.9989 & 0.19 \\
\hline
\end{tabular}

$Y$ : peak area; $X$ : concentration $(\mu \mathrm{g} / \mathrm{mL}) ; S_{a}$ : standard deviation of the slope; $S_{b}$ : standard deviation of the intercept.

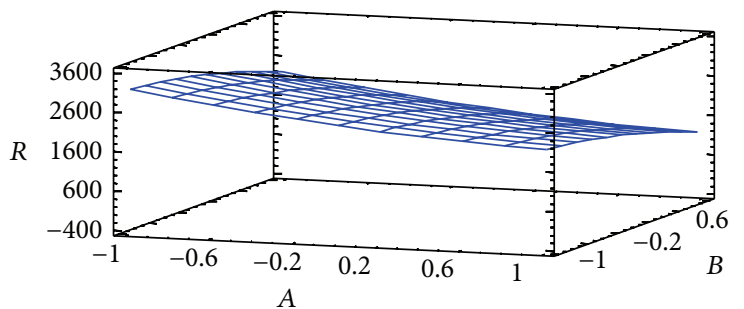

(a)

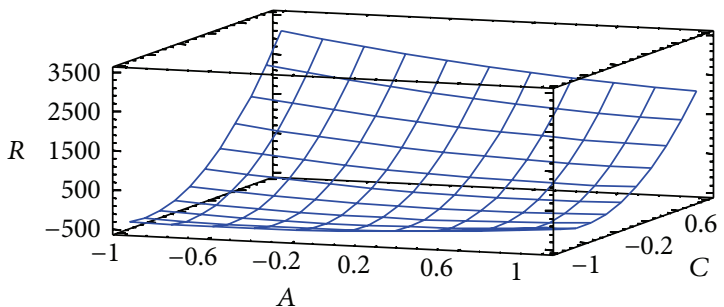

(b)

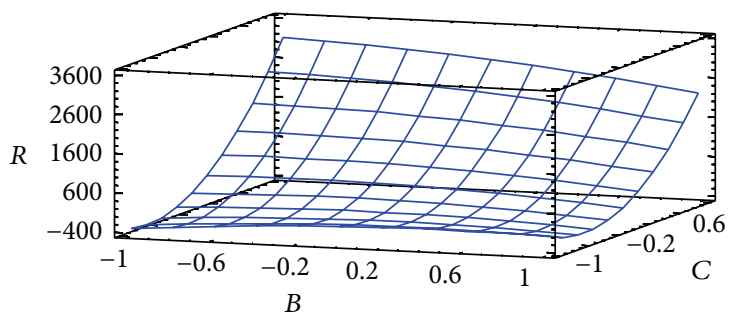

(c)

Figure 2: Response surface plots for BBD: (a) $\mathrm{pH}(A)$ versus flow rate $(B)$ (mobile phase ratio: 95\%); (b) pH $(A)$ versus mobile phase ratio $(C)$ (flow rate: $1.0 \mathrm{~mL} / \mathrm{min})$; (c) flow rate $(B)$ versus mobile phase ratio $(C)(\mathrm{pH}: 6.0)$.

particular, the effect of $\mathrm{pH}(A)$ and mobile phase ratio $(C)$ on resolution is shown in Figure 2(b). This plot shows that the highest resolution is obtained at greater values of the mobile phase ratio. The relation between the effects of the other variables on the resolution is also plotted in Figures 2(a) $-2(\mathrm{c})$.

According to the results of the optimization procedure, the optimum variables corresponded to $\mathrm{pH}, 6.0$; flow rate, $1.0 \mathrm{~mL} / \mathrm{min}$; mobile phase ratio, $95 \%$. A typical chromatogram obtained under optimum conditions is shown in Figure 3.

3.2. Validation of the HPLC Method. The results of the linearity, LODs, and LOQs are summarized in Table 4. A good linear relationship is displayed between the corresponding peak areas and the concentrations of the compounds based on the correlation coefficients $\left(r^{2}>0.9962\right)$. The LODs of the six compounds were in the range of $0.10-0.19 \mu \mathrm{g} / \mathrm{mL}$, and the LOQs of the six compounds were in the range of 0.33$0.63 \mu \mathrm{g} / \mathrm{mL}$. So, these values demonstrated that the proposed

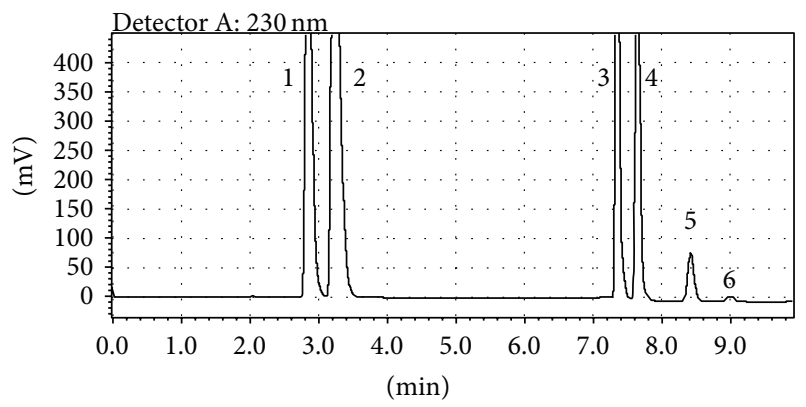

Figure 3: Chromatogram of synthetic standard mixture containing five food additives and caffeine recorded under optimized analysis conditions (1: sodium benzoate $(15 \mu \mathrm{g} / \mathrm{mL}), 2$ : potassium sorbate $(15 \mu \mathrm{g} / \mathrm{mL}), 3$ : caffeine $(15 \mu \mathrm{g} / \mathrm{mL}), 4$ : ponceau $4 \mathrm{R}(6 \mu \mathrm{g} / \mathrm{mL}), 5$ : allura red $(6 \mu \mathrm{g} / \mathrm{mL})$, and 6: carmoisine $(6 \mu \mathrm{g} / \mathrm{mL}))$.

analytical method was sufficiently sensitive. A summary of intraday (the RSD of the recoveries of the nine samples) and 


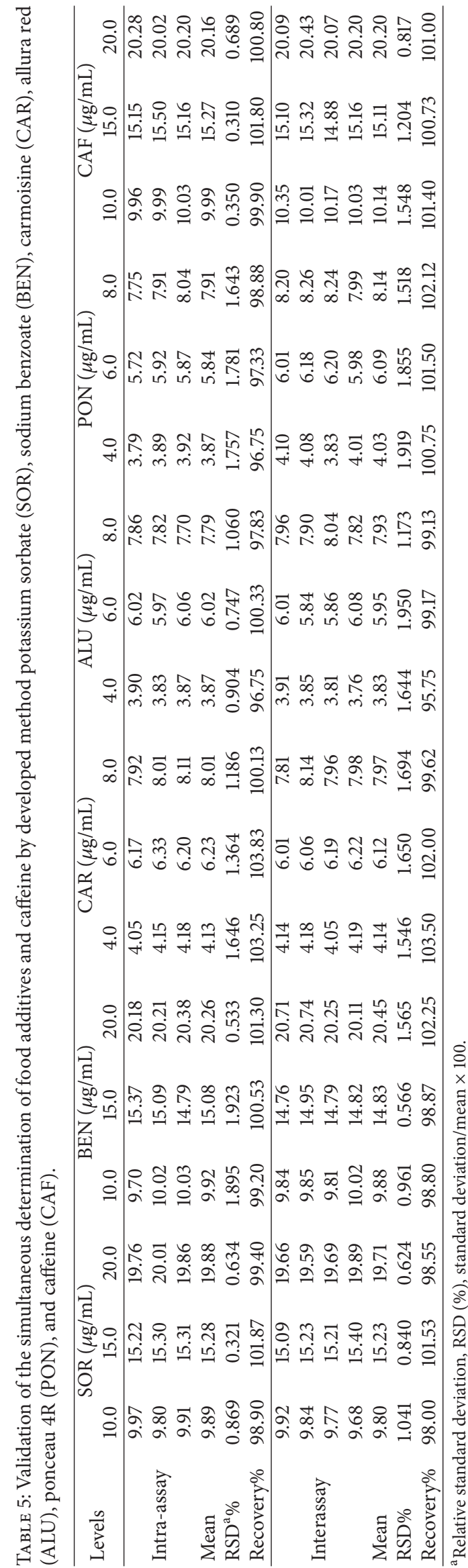


TABLE 6: Results of accuracy studies (mean value \pm standard deviation, $n=5$ ).

\begin{tabular}{|c|c|c|c|c|c|}
\hline Sample & Food additive & Sample concentration $(\mu \mathrm{g} / \mathrm{mL})$ & Added $(\mu \mathrm{g} / \mathrm{mL})$ & Found $(\mu \mathrm{g} / \mathrm{mL})$ & Recovery (\%) \\
\hline \multirow{9}{*}{ Energy drink } & \multirow{3}{*}{ Potassium sorbate } & \multirow{3}{*}{10.68} & 3 & $13.70 \pm 0.048$ & 100.67 \\
\hline & & & 6 & $16.90 \pm 0.057$ & 103.67 \\
\hline & & & 9 & $20.00 \pm 0.065$ & 103.56 \\
\hline & \multirow{3}{*}{ Caffeine } & \multirow{3}{*}{7.11} & 3 & $10.18 \pm 0.045$ & 102.33 \\
\hline & & & 6 & $13.25 \pm 0.054$ & 102.33 \\
\hline & & & 9 & $16.61 \pm 0.042$ & 105.56 \\
\hline & \multirow{3}{*}{ Allura red } & \multirow{3}{*}{3.26} & 1 & $4.31 \pm 0.038$ & 105.00 \\
\hline & & & 2 & $5.34 \pm 0.037$ & 104.00 \\
\hline & & & 3 & $6.39 \pm 0.044$ & 104.33 \\
\hline \multirow{12}{*}{ Pomegranate juice } & \multirow{3}{*}{ Potassium sorbate } & \multirow{3}{*}{12.71} & 3 & $15.64 \pm 0.059$ & 97.67 \\
\hline & & & 6 & $18.61 \pm 0.103$ & 98.33 \\
\hline & & & 9 & $21.74 \pm 0.166$ & 100.34 \\
\hline & \multirow{3}{*}{ Sodium benzoate } & \multirow{3}{*}{7.24} & 3 & $10.34 \pm 0.040$ & 103.60 \\
\hline & & & 6 & $13.30 \pm 0.054$ & 101.20 \\
\hline & & & 9 & $16.45 \pm 0.063$ & 102.50 \\
\hline & \multirow{3}{*}{ Carmoisine } & \multirow{3}{*}{1.21} & 1 & $2.25 \pm 0.012$ & 104.00 \\
\hline & & & 2 & $3.30 \pm 0.017$ & 104.50 \\
\hline & & & 3 & $4.34 \pm 0.022$ & 104.40 \\
\hline & \multirow{3}{*}{ Ponceau 4R } & \multirow{3}{*}{4.08} & 1 & $5.11 \pm 0.036$ & 102.66 \\
\hline & & & 2 & $6.16 \pm 0.039$ & 104.16 \\
\hline & & & 3 & $7.15 \pm 0.045$ & 102.22 \\
\hline
\end{tabular}

interday precision (the RSD of the recoveries of the twelve samples) are listed in Table 5. The RSD values ranged from $0.310 \%$ to $1.950 \%$ for the HPLC method. These results show that the proposed method is precise for the simultaneous determination of these compounds. The recoveries of the six compounds to determine the accuracy of the method are summarized in Table 6 . The proposed method resulted in satisfactory recoveries for all additives and caffeine, ranging from $97.67 \%$ to $105.56 \%$. The recoveries demonstrated that the matrixes have negligible effect on the quantification of these compounds and the method is accurate within the desired range. Under refrigerated and room temperature conditions, all food additives and caffeine in mobile phase and water were stable for at least 1 month.

These results show that the proposed method is precise, accurate, and sensitive for the simultaneous determination of the six compounds and can be used for routine analysis of potassium sorbate, sodium benzoate, carmoisine, allura red, ponceau $4 \mathrm{R}$, and caffeine in soft drinks.

3.3. Application of the Method. The proposed HPLC method was applied to the simultaneous determination of potassium sorbate, sodium benzoate, carmoisine, allura red, ponceau $4 \mathrm{R}$, and caffeine in different soft drinks. Five replicates determination was made and the results are summarized in Table 7 . The concentration of food additives in soft drinks ranged from $24.26 \pm 0.47 \mu \mathrm{g} / \mathrm{mL}$ to $254.13 \pm 1.24 \mu \mathrm{g} / \mathrm{mL}$. The amounts of food additives and caffeine in all soft drink samples were below the limit value defined in the legislation on the food additives $[1,2]$.
TABLE 7: Analysis of soft drinks (mean value \pm standard deviation, $n=5)$.

\begin{tabular}{lccc}
\hline Food additive & $\begin{array}{c}\text { Energy drink } \\
(\mu \mathrm{g} / \mathrm{mL})\end{array}$ & $\begin{array}{c}\text { Pomegranate } \\
\text { juice } \\
(\mu \mathrm{g} / \mathrm{mL})\end{array}$ & $\begin{array}{c}\text { Mandarin } \\
\text { juice } \\
(\mu \mathrm{g} / \mathrm{mL})\end{array}$ \\
\hline Potassium sorbate & $213.62 \pm 0.34$ & $254.13 \pm 1.24$ & $246.23 \pm 1.76$ \\
Sodium benzoate & - & $144.71 \pm 2.38$ & $148.67 \pm 1.99$ \\
Caffeine & $142.20 \pm 1.17$ & - & - \\
Allura red & $65.28 \pm 0.59$ & - & - \\
Carmoisine & - & $24.26 \pm 0.47$ & - \\
Ponceau 4R & - & $81.58 \pm 1.51$ & - \\
\hline
\end{tabular}

\section{Conclusion}

An efficient, accurate, and reliable method for the simultaneous determination of five food additives and caffeine in soft drinks was developed using HPLC. Box-Behnken design was applied to the optimization of the chromatographic separation conditions and this design reduced to the number of experiments required. It can be concluded that a slight change in mobile phase ratio has a direct effect on the resolution. All the validation parameters were within the acceptance range. High percentage recovery data also shows that the proposed method is free from the interference. Consequently, this study will provide a sensitive and rapid method for the detection of potassium sorbate, sodium benzoate, carmoisine, allura red, ponceau $4 \mathrm{R}$, and caffeine in soft drinks. 


\section{Conflict of Interests}

The authors declare that there is no conflict of interests regarding the publication of this paper.

\section{Acknowledgment}

This work was financially supported by Yildiz Technical University Research Foundation (Project no. 2010-01-01-GEP04).

\section{References}

[1] Regulation (EC) no 1333/2008 of the European Parliament and of the Council on Food Additives, 2008.

[2] European Commission, Commission Directive 2008/84/EC, Laying down Specific Purity Criteria on Food Additives Other Than Colours and Sweeteners, 2008.

[3] A. K. Malik, C. Blasco, and Y. Pico, "Liquid chromatographymass spectrometry in food safety," Journal of Chromatography A, vol. 1217, no. 25, pp. 4018-4040, 2010.

[4] I. Baranowska, M. Zydroń, and K. Szczepanik, "TLC in the analysis of food additives," Journal of Planar ChromatographyModern TLC, vol. 17, no. 1, pp. 54-57, 2004.

[5] E. Dinç, E. Baydan, M. Kanbur, and F. Onur, "Spectrophotometric multicomponent determination of sunset yellow, tartrazine and allura red in soft drink powder by double divisor-ratio spectra derivative, inverse least-squares and principal component regression methods," Talanta, vol. 58, no. 3, pp. 579-594, 2002.

[6] S. Altinöz and S. Toptan, "Simultaneous determination of Indigotin and Ponceau-4R in food samples by using Vierordt's method, ratio spectra first order derivative and derivative UV spectrophotometry," Journal of Food Composition and Analysis, vol. 16, no. 4, pp. 517-530, 2003.

[7] A. H. Alghamdi, "Determination of allura red in some food samples by adsorptive stripping voltammetry," Journal of $A O A C$ International, vol. 88, no. 5, pp. 1387-1393, 2005.

[8] X. Yang, H. Qin, M. Gao, and H. Zhang, "Simultaneous detection of Ponceat $4 \mathrm{R}$ and tartrazine in food using adsorptive stripping voltammetry on an acetylene black nanoparticlemodified electrode," Journal of the Science of Food and Agriculture, vol. 91, no. 15, pp. 2821-2825, 2011.

[9] S. Chanlon, L. Joly-Pottuz, M. Chatelut, O. Vittori, and J. L. Cretier, "Determination of carmoisine, allura red and ponceau $4 \mathrm{R}$ in sweets and soft drinks by differential pulse polarography," Journal of Food Composition and Analysis, vol. 18, no. 6, pp. 503515, 2005.

[10] M. A. Prado, L. F. V. Boas, M. R. Bronze, and H. T. Godoy, "Validation of methodology for simultaneous determination of synthetic dyes in alcoholic beverages by capillary electrophoresis," Journal of Chromatography A, vol. 1136, no. 2, pp. 231-236, 2006.

[11] N. Dossi, R. Toniolo, S. Susmel, A. Pizzariello, and G. Bontempelli, "Simultaneous RP-LC determination of additives in soft drinks," Chromatographia, vol. 63, no. 11-12, pp. 557-562, 2006.

[12] N. O. Can, G. Arlı, and Y. Lafçı, "A novel RP-HPLC method for simultaneous determination of potassium sorbate and sodium benzoate in soft drinks using C18-bonded monolithic silica column," Journal of Separation Science, vol. 34, no. 16-17, pp. 2214-2222, 2011.

[13] Q. H. Yan, L. Yang, H. R. Zhang, and L. Y. A. Niu, "A sensitive and validated method for determination of four additives in ham sausage by HPLC-DAD method," Journal of Liquid Chromatography \& Related Technologies, vol. 35, no. 2, pp. 268279, 2012.

[14] K. Ma, Y. N. Yang, X. X. Jiang, M. Zhao, and Y. Q. Cai, "Simultaneous determination of 20 food additives by high performance liquid chromatography with photo-diode array detector," Chinese Chemical Letters, vol. 23, no. 4, pp. 492-495, 2012.

[15] M. Ma, X. Luo, B. Chen, S. Su, and S. Yao, "Simultaneous determination of water-soluble and fat-soluble synthetic colorants in foodstuff by high-performance liquid chromatography-diode array detection-electrospray mass spectrometry," Journal of Chromatography A, vol. 1103, no. 1, pp. 170-176, 2006.

[16] H. Gao, M. Yang, M. Wang, Y. Zhao, Y. Cao, and X. Chu, "Determination of 30 synthetic food additives in soft drinks by HPLC/electrospray ionization-tandem mass spectrometry," Journal of AOAC International, vol. 96, no. 1, pp. 110-115, 2013.

[17] F. Feng, Y. Zhao, W. Yong, L. Sun, G. Jiang, and X. Chu, "Highly sensitive and accurate screening of 40 dyes in soft drinks by liquid chromatography-electrospray tandem mass spectrometry," Journal of Chromatography B, vol. 879, no. 20, pp. 1813-1818, 2011.

[18] R. Noguerol-Cal, J. M. López-Vilariño, M. V. GonzálezRodríguez, and L. F. Barral-Losada, "Development of an ultraperformance liquid chromatography method for improved determination of additives in polymeric materials," Journal of Separation Science, vol. 30, no. 15, pp. 2452-2459, 2007.

[19] R. Gheshlaghi, J. M. Scharer, M. Moo-Young, and P. L. Douglas, "Application of statistical design for the optimization of amino acid separation by reverse-phase HPLC," Analytical Biochemistry, vol. 383, no. 1, pp. 93-102, 2008.

[20] D. C. Montgomery, Design and Analysis of Experiments, John Wiley \& Sons, New York, NY, USA, 2004.

[21] S. L. C. Ferreira, R. E. Bruns, E. G. P. da Silva et al., "Statistical designs and response surface techniques for the optimization of chromatographic systems," Journal of Chromatography A, vol. 1158, no. 1-2, pp. 2-14, 2007.

[22] D. B. Hibbert, "Experimental design in chromatography: a tutorial review," Journal of Chromatography B: Analytical Technologies in the Biomedical and Life Sciences, vol. 910, no. 1, pp. 2-13, 2012.

[23] F. van de Velde, M. E. Pirovani, M. S. Cámara, D. R. Güemes, and C. M. D. H. Bernardi, "Optimization and validation of a UV-HPLC method for vitamin C determination in strawberries (Fragaria ananassa Duch.), using experimental designs," Food Analytical Methods, vol. 5, no. 5, pp. 1097-1104, 2012.

[24] N. García-Villar, J. Saurina, and S. Hernández-Cassou, "Highperformance liquid chromatographic determination of biogenic amines in wines with an experimental design optimization procedure," Analytica Chimica Acta, vol. 575, no. 1, pp. 97105, 2006.

[25] T. Sivakumar, R. Manavalan, C. Muralidharan, and K. Valliappan, "Multi-criteria decision making approach and experimental design as chemometric tools to optimize HPLC separation of domperidone and pantoprazole," Journal of Pharmaceutical and Biomedical Analysis, vol. 43, no. 5, pp. 1842-1848, 2007.

[26] M. Medenica, B. Jancic, D. Ivanovic, and A. Malenovic, "Experimental design in reversed-phase high-performance liquid chromatographic analysis of imatinib mesylate and its impurity," Journal of Chromatography A, vol. 1031, no. 1-2, pp. 243-248, 2004 . 
[27] G. Iriarte, N. Ferreirós, I. Ibarrondo et al., "Optimization via experimental design of an SPE-HPLC-UV-fluorescence method for the determination of valsartan and its metabolite in human plasma samples," Journal of Separation Science, vol. 29, no. 15, pp. 2265-2283, 2006.

[28] E. Nemutlu, S. Kır, D. Katlan, and M. S. Beksaç, "Simultaneous multiresponse optimization of an HPLC method to separate seven cephalosporins in plasma and amniotic fluid: application to validation and quantification of cefepime, cefixime and cefoperazone," Talanta, vol. 80, no. 1, pp. 117-126, 2009.

[29] International Conference on Harmonization (ICH) of Technical Requirements for Registration of Pharmaceuticals for Human Use, Topic Q2 (R1): Validation of Analytical Procedures: Text and Methodology, International Conference on Harmonization (ICH), Geneva, Switzerland, 2005.

[30] J.-Z. Song, C.-F. Qiao, S.-L. Li, Y. Zhou, M.-T. Hsieh, and H.$\mathrm{X}$. Xu, "Rapid optimization of dual-mode gradient high performance liquid chromatographic separation of Radix et Rhizoma Salviae Miltiorrhizae by response surface methodology," Journal of Chromatography A, vol. 1216, no. 42, pp. 7007-7012, 2009. 

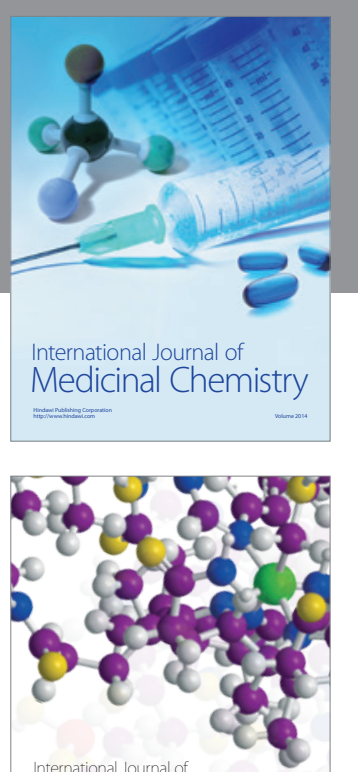

Carbohydrate Chemistry

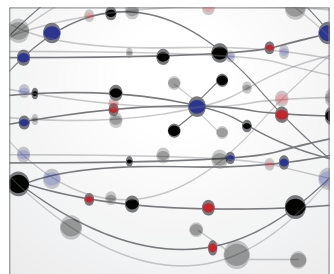

The Scientific World Journal
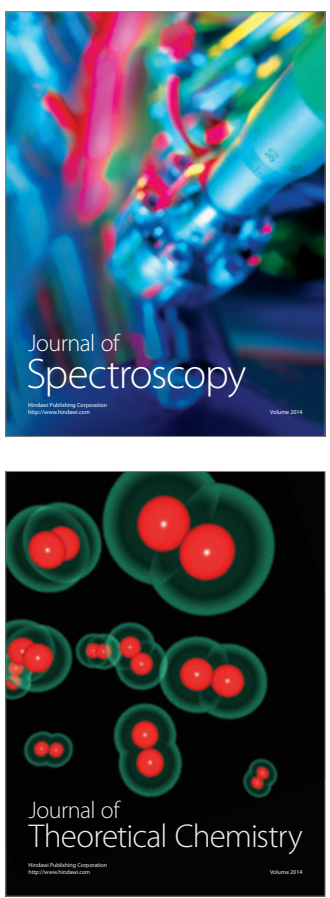
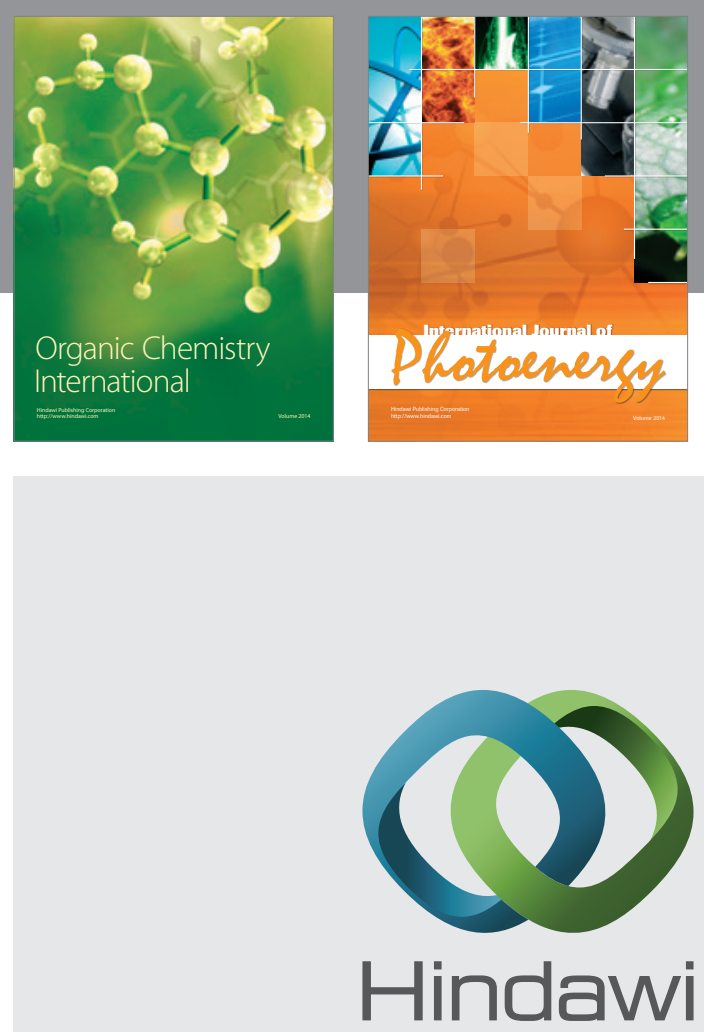

Submit your manuscripts at

http://www.hindawi.com

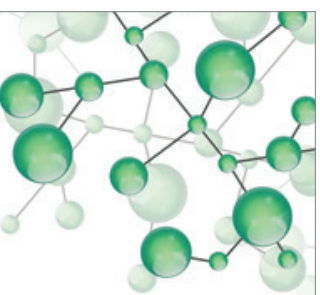

International Journal of

Inorganic Chemistry

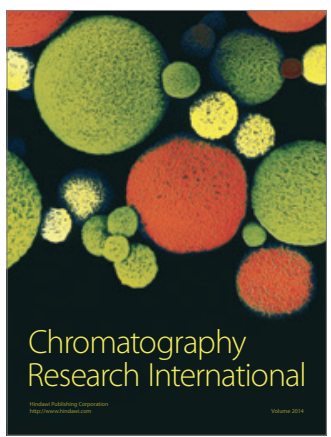

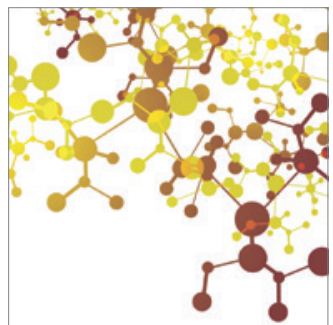

Applied Chemistry
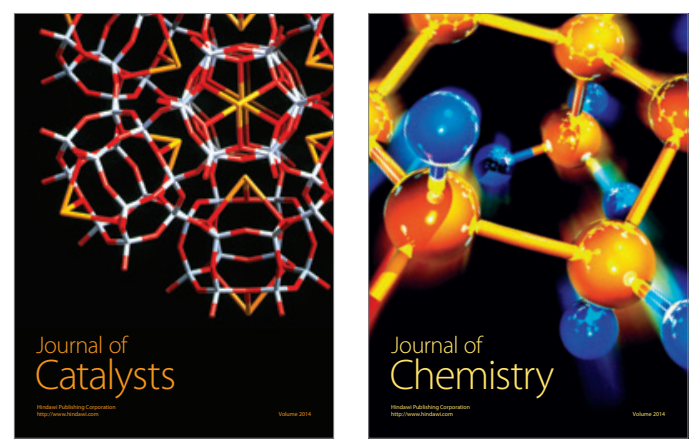
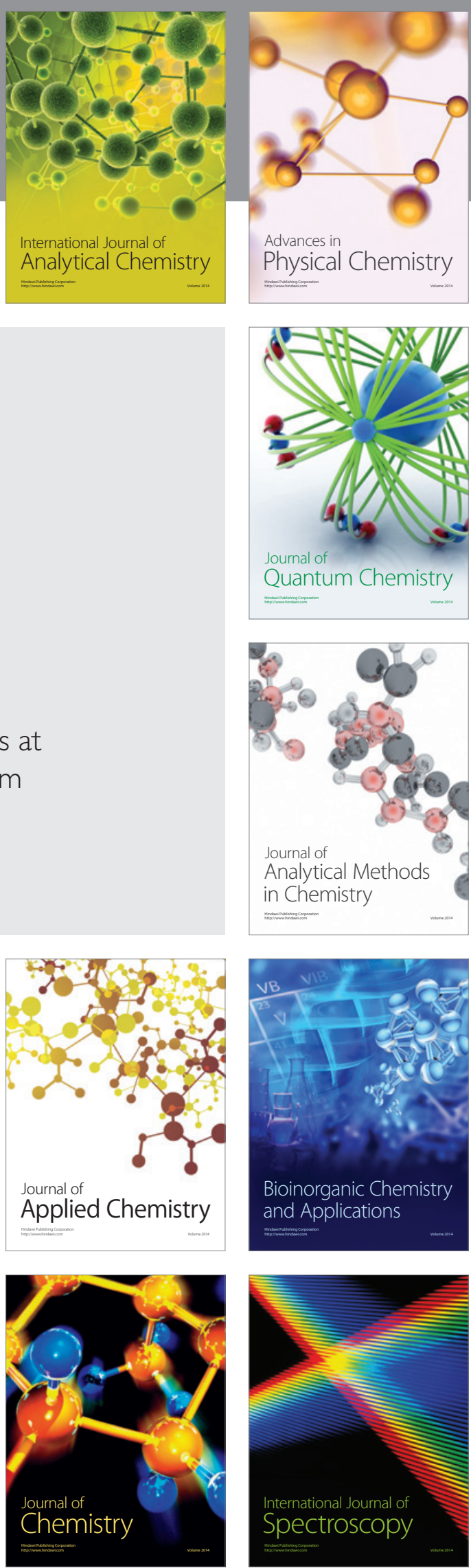